\title{
THE BERTRAND MODEL AND THE DEGREE OF PRODUCT DIFFERENTIATION
}

\author{
Ciprian RUSESCU \\ Bucharest University of Economic Studies, Romania \\ rusescuciprian18@stud.ase.ro
}

\begin{abstract}
Imperfect competition exists in the current economic climate. It can manifest in relation with product quantity (Cournot type), product price (Bertrand type) or quality. The purpose of this paper is to analyze a duopoly market where a Bertrand behavior is adopted by the firms. Regardless the level of product differentiation, both firms are expected to survive and a stable equilibrium will manifest. In a non differentiation scenario (homogeneous goods), with identical quantities being sold, the selling price will match the marginal cost and duopoly profit will be zero, situation known as Bertrand's Paradox.
\end{abstract}

Keywords: Bertrand model, Bertrand paradox, oligopoly, product differentiation.

JEL classification: C72, D01, D43, L13

DOI: $10.12948 / \mathrm{ie} 2019.07 .07$

\section{Introduction}

The theory of oligopoly has a long and distinguished history. Dating back two centuries ago the first studies identify a phased evolution of the oligopoly theory with an initial traditional stage, where monopoly/competitive behaviors were analyzed, followed by a later stage where games theory was applied to better understand the oligopoly behaviors (John von Neumann and Oskar Morgenstern - (1944)) while various oligopoly models were developed to mirror real market conditions (see Joe Bain (1956), Paolo Sylos Labini (1957) works and Franco Modigliani's papers (1958)).

Representing the traditional stage, Augustine Cournot and Joseph Louis Francois Bertrand's models stand out (with the two scientist being later named by Xavier Vives "founding fathers of oligopoly theory" (2001)). Cournot presents a duopoly market, with firms producing homogeneous goods and competing in quantities, while Bertrand was advocating price competition. Initially written as a review of Cournot's theory, Bertrand's approach (1883) proved to be the most used model in price competition scenarios. His base assumptions were: existence of at least two competing firms producing homogeneous goods, equal awareness of market demand, price competition scenario, simultaneous price set up with consumers choosing to buy from the firm offering lowest price, or equally from each firm, in case of matching price.

Current oligopoly literature contain numerous studies based on Bertrand model. Using Dixit's general principles (1979), Singh \& Vives (1984) highlight quantity competition (substitute goods) and price competition (complementary goods) as the dominant strategies. Using a different approach, Hackner (2000), Zanchettin (2006) and Tremblay (2011) consider that informational asymmetry (including demand's asymmetry) can trigger optimality of Bertrand or Cournot-Bertrand models. Regardless the approach demand and cost function linearity were the common link of the majority of the studies (Ahmed et all (2006), Zhang et all (2009), 
www.conferenceie.ase.ro

Tremblay (2011)) with demand non-linearity being analyzed by Ahmed, Alsadany \& Puu (2015) and Yi \& Zeng (2015) developing a model using cost function non-linearity.

Another important step in the oligopoly theory development is the so-called Cournot-Bertrand duality theory, first noted by Sonnenschein (1968) offering the dual perspective of the Cournot/Bertrand competition (substitute goods) respectively the Bertrand/Cournot competition (complementary goods) as having the same strategic properties (Singh \& Vives, 1984). Studying one model should be enough, as the other one will follow similar principles. The next paragraphs of this paper will investigate the impact of product differentiation on Bertrand static equilibrium model highlighting aspects such as the firm stability and survival potential as well as the product differentiation impact on Nash equilibrium theory. The principals of the related mathematic model are presented next.

\section{The model}

The scenario used is one with high consumers number but only two producers of differentiated goods; analyzed below is the potential market equilibrium with consumers targeting to maximize their own satisfaction seen as the difference between own utility function and price for purchasing required quantities of products, without any budgetary constraints:

$$
S=U\left(q_{1}, q_{2}\right)-\sum_{i=1}^{2} p_{i} q_{i}
$$

Mathematically, the utility function is considered to be non-linear (quadratic), with separable variables and also strictly concave, as per bellow:

$$
U\left(q_{1}, q_{2}\right)=\alpha_{1} q_{1}+\alpha_{2} q_{2}-\frac{\beta_{1} q_{1}^{2}+2 d q_{1} q_{2}+\beta_{2} q_{2}^{2}}{2}
$$

where $\alpha_{i}>0, \beta_{i}>0, d \epsilon[0 ; 1], \beta_{1} \beta_{2}-d^{2}>0, \alpha_{i} \beta_{j}-\alpha_{j} d>0(\forall) i=\overline{1,2}$

Using $\alpha_{1}=\alpha_{2}=\mathrm{a}, \beta_{1}=\beta_{2}=1$ as assumptions, the utility function becomes:

$$
U\left(q_{1}, q_{2}\right)=a\left(q_{1}+q_{2}\right)-\frac{q_{1}^{2}+2 d q_{1} q_{2}+q_{2}^{2}}{2}
$$

This is expected to determine a linear demand functions which inverse is:

$$
\begin{aligned}
& p_{1}=a-q_{1}-d q_{2} \rightarrow q_{1}=\frac{\mathrm{a}(1-d)}{1-d^{2}}-\frac{1}{1-d^{2}} * p_{1}+\frac{d}{1-d^{2}} * p_{2} \\
& p_{2}=a-q_{2}-d q_{1} \rightarrow q_{2}=\frac{\mathrm{a}(1-d)}{1-d^{2}}-\frac{1}{1-d^{2}} * p_{2}+\frac{d}{1-d^{2}} * p_{1}
\end{aligned}
$$

a system similar to those already used by Dixit (1979), Singh \& Vives (1984), Imperato et all (2004), Tremblay (2011), under positivity restriction, where "d"indicates the nature of the goods: positive values for substitutes goods, negatives values for complements, while zero values representing independent goods. Demand function for " $i$ " good, decreases in its price, but increases/decreases in rival's price if case of substitute goods/ complements.

It can be noted that $\mathrm{d} \neq 1$ at this stage. 
As regards the production cost, this is considered identical for both firms and expressed by a linear function $\left(\mathrm{C}=\mathrm{c}^{*} \mathrm{q}\right)$ matching the marginal cost. Based on these assumptions, the profit can be expressed as per below:

$$
\pi_{i}=\left(p_{i}-c\right) q_{i},(\forall) i=\overline{1,2}
$$

Marginal profits as well as all Appendix A calculations, leads to Nash equilibrium values:

$$
p_{1}^{*}=p_{2}^{*}=\frac{a(1-d)+c}{2-d}(3) \quad q_{1}^{*}=q_{2}^{*}=\frac{a-c}{(1+d)(2-d)}(4) \quad \pi_{1}^{*}=\pi_{2}^{*}=\frac{(a-c)^{2}(1-d)}{(2-d)^{2}(1+d)}
$$

The results obtained so far lead to the following initial conclusions:

- If $\mathrm{d}=0$ the model confirms that both players act as monopolists;

- Both firms have the same Nash equilibrium behavior (values);

- If " $d$ " increases up to 1, equilibrium becomes more competitive - price and profit decreases.

To further analyze the stability of the Nash equilibrium we need to start with the necessary and sufficient stability condition (Dixit, 1986): $\left|\pi_{i i}\right|>\left|\pi_{i j}\right|$, where $\pi_{i i}=\frac{\partial^{2} \pi_{i}}{\partial p_{i}^{2}}$ iar $\pi_{i j}=\frac{\partial^{2} \pi_{i}}{\partial p_{j}^{2}}$, $i, j=\overline{1,2}$

$$
\left\{\begin{array}{l}
\frac{\partial^{2} \pi_{1}}{\partial p_{1}^{2}}>\frac{\partial^{2} \pi_{1}}{\partial p_{1} p_{2}} \\
\frac{\partial^{2} \pi_{2}}{\partial p_{2}^{2}}>\frac{\partial^{2} \pi_{2}}{\partial p_{2} p_{1}}
\end{array} \rightarrow\left|\frac{-2}{1-d^{2}}\right|>\left|\frac{d}{1-d^{2}}\right| \rightarrow \frac{1}{1-d^{2}}>\frac{d}{2\left(1-d^{2}\right)} \stackrel{d \epsilon(0 ; 1)}{\longrightarrow} 2>d(A) .\right.
$$

Conclusion: equilibrium is stable $(\forall) d \in(0 ; 1)$.

Next paragraphs will analise the $\mathrm{d}=1$ scenario - perfectly substitutes goods. Therefore we have $\frac{\partial U}{\partial q_{\mathrm{i}}}=\mathrm{a}-q_{\mathrm{i}}-q_{\mathrm{j}}=p_{i},(\forall) i, j=\overline{1,2}$, then $\mathrm{p}_{\mathrm{i}}=\mathrm{p}_{\mathrm{j}}=\mathrm{p}$ and further $q_{i}+q_{j}=a-p$.

Consumers will choose to buy at the best price, however price being identical and no individual preferences, market demand will be perfectly split between the two producers. Thus $q_{i}=q_{j}=\frac{a-p}{2}$ (6), profit becomes $\pi_{i}=(p-c) q_{i}=(p-c) \frac{a-p}{2}=\frac{a p-p^{2}-a c+c p}{2}$. First order condition leads to:

$$
p=\frac{a+c}{2}(7) \rightarrow q_{i}=q_{j}=\frac{a-c}{2}=q(8) \rightarrow \pi_{i}=\pi_{j}=\frac{(a-c)^{2}}{4}=\pi(9)
$$

Comparing (6) and (8) above is obvious that $p=c$, resulting $\pi=0$.

Nash equilibrium is profit maximizer for the player $\mathrm{i}$, regardless player $\mathrm{j}$ behavior, conclusion mathematically expressed as per fellow:

$$
\left\{\begin{array}{l}
\pi^{i}\left(p_{i}^{*}, p_{j}^{*}\right) \geq \pi^{i}\left(p_{i}, p_{j}^{*}\right)(\forall) i, j=\overline{1,2} \\
\pi^{j}\left(p_{i}^{*}, p_{j}^{*}\right) \geq \pi^{j}\left(p_{i}, p_{j}\right)(\forall) i, j=\overline{1,2}
\end{array}\right.
$$

Proposition: $p_{1}=p_{2}=c$ and $\pi_{1}^{*}=\pi_{2}^{*}=0$ defines the only Nash equilibrium. 
Proof: as already mentioned above, demand for the "i" product depends on the price set up by the rival firm (Machado, Economia Industrial) and is expressed as follows:

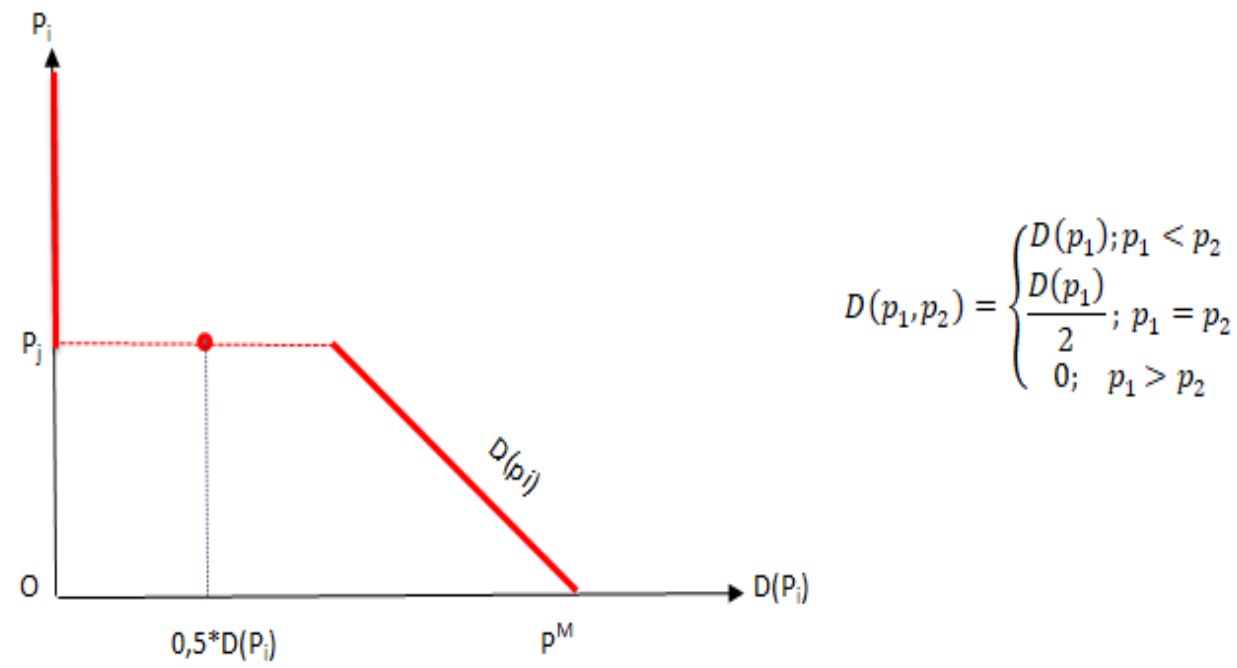

Figure 1. Firm's “ $i$ ” demand function and its dependence of rival's price

In any duopoly scenario, we may have one of the following situations:

a) $\mathrm{P}_{1}{ }^{*}>\mathrm{P}_{2}{ }^{*}>\mathrm{c}$. Thus $D\left(p_{1}\right)=0 \rightarrow \pi_{1}=0, D\left(p_{2}\right)=D\left(p_{2}^{*}\right) \rightarrow \pi_{2}=\left(p_{2}^{*}-c\right) D\left(p_{2}\right)>0$

First player optimal response would have been $\mathrm{P}_{1}{ }^{*}=\mathrm{P}_{2}^{*}-\varepsilon$, generating positive profit.

b) $\mathrm{P}_{1}{ }^{*}=\mathrm{P}_{2}{ }^{*}>c$. In this case $\pi_{1}^{*}=\left(p_{1}^{*}-c\right) \frac{D\left(p_{1}\right)}{2}, \pi_{2}^{*}=\left(p_{2}^{*}-c\right) \frac{D\left(p_{2}\right)}{2}$

First player optimal response would have been $\mathrm{P}_{1}{ }^{\prime}=\mathrm{P}_{2}{ }^{*}-\varepsilon$ which would lead to the seizure of the entire demand, so $D\left(p_{1}\right)=D\left(p_{1}^{\prime}\right)$ therefore $\pi_{1}^{\prime}=\left(p_{1}^{\prime}-c\right) D\left(p_{1}^{\prime}\right)>\left(p_{1}^{*}-c\right) \frac{D\left(p_{1}\right)}{2}=\pi_{1}^{*}$ c) $\mathrm{P}_{1}{ }^{*}>\mathrm{P}_{2}{ }^{*}=\mathrm{c}$. Then $D\left(p_{1}\right)=0 \rightarrow \pi_{1}=0, D\left(p_{2}\right)=D\left(p_{2}^{*}\right) \rightarrow \pi_{2}=(c-c) D\left(p_{2}\right)=0$ Second player optimal response would be $\mathrm{P}_{2}{ }^{\prime}=\mathrm{P}_{1}{ }^{*}-\varepsilon$ and $\pi_{2}^{\prime}=\left(p_{2}^{\prime}-c\right) D\left(p_{2}^{\prime}\right)>0=\pi_{2}^{*}$

d) $\mathrm{P}_{1}{ }^{*}=\mathrm{P}_{2}{ }^{*}=\mathrm{c}$. Then $D\left(p_{1}\right)=D\left(p_{2}\right)=\frac{D\left(p_{1}, p_{2}\right)}{2} \rightarrow \pi_{1}=\pi_{2}=(c-c) \frac{D\left(p_{1}, p_{2}\right)}{2}=0$ If $\mathrm{P}_{1} \downarrow \rightarrow \pi_{1}=\left(p_{1}^{*}-\varepsilon-c\right) D\left(p_{1}-\varepsilon\right)<0=\pi_{1}^{*}$ and if $\mathrm{P}_{1} \lambda \rightarrow \mathrm{P}_{1}>\mathrm{P}_{2} \rightarrow D\left(p_{1}\right)=0=\pi_{1}^{*}$. Any action path the first player would take, would lead to a smaller profit then the one expected from the current strategy, therefore he is not motivated to modify its price triggering the unique Nash equilibrium point.

Conclusion: in case of homogeneous goods (perfectly substitutable), equilibrium is stable, with the price being equal to marginal cost, at which both producers offer half of the existing market output whilst individual and aggregate profit is zero - scenario known in specialized literature as the Bertrand Paradox.

Optimal response of player " $\mathrm{i}$ " to player " $\mathrm{j}$ " actions, is described by the reaction function:

$$
R_{i}\left(p_{j}\right)=\left\{\begin{array}{c}
p_{M} ; p_{j}<p_{M} \\
p_{j}-\varepsilon ; c<p_{j} \leq p_{M} \\
c ; \quad p_{j} \leq c
\end{array}\right.
$$

We further graphically analyze the sensitivity of the price/quantity/profit to the changes in the level of product differentiation (values of parameter d) in a Nash equilibrium scenario. Using the formulas in Appendix B as starting point and customizing parameters a and c ( $\mathrm{a}=80 \mathrm{EUR}$, 
www.conferenceie.ase.ro

$\mathrm{c}=30 \mathrm{EUR}$ ) we have gradually increased product homogeneity degree by ratio of 0.05 (from the independent goods specific value $(d=0)$ to homogeneous goods specific value one $(d=1))$

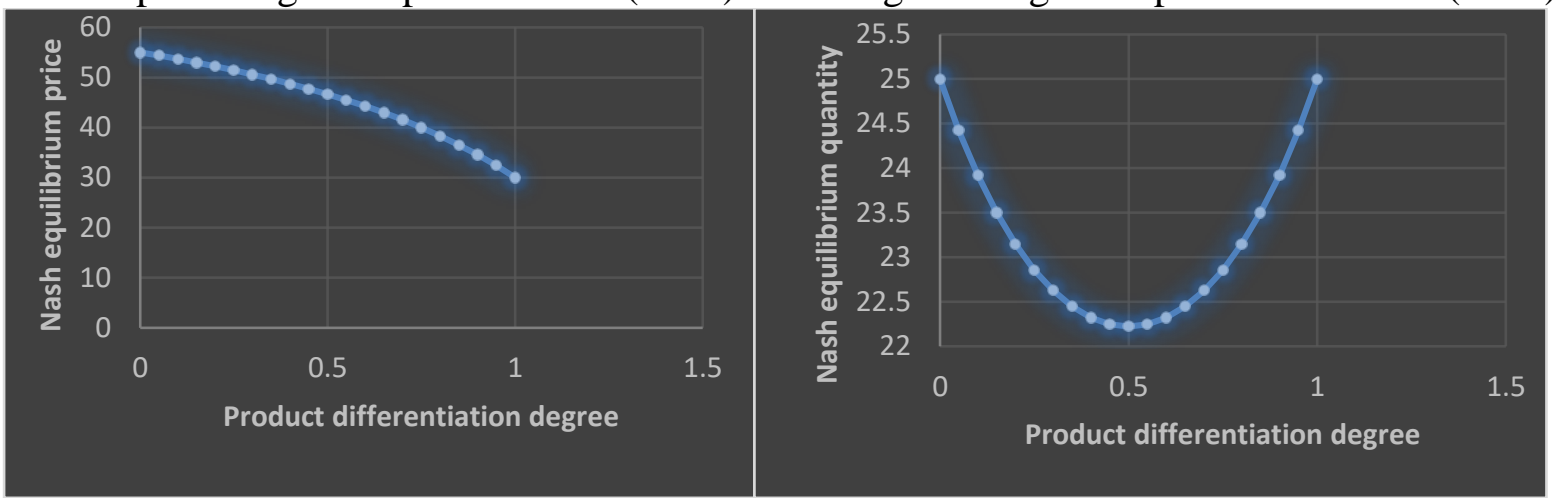

Figure 2. Nash equilibrium price evolution

Figure 3. Nash equilibrium quantity evolution

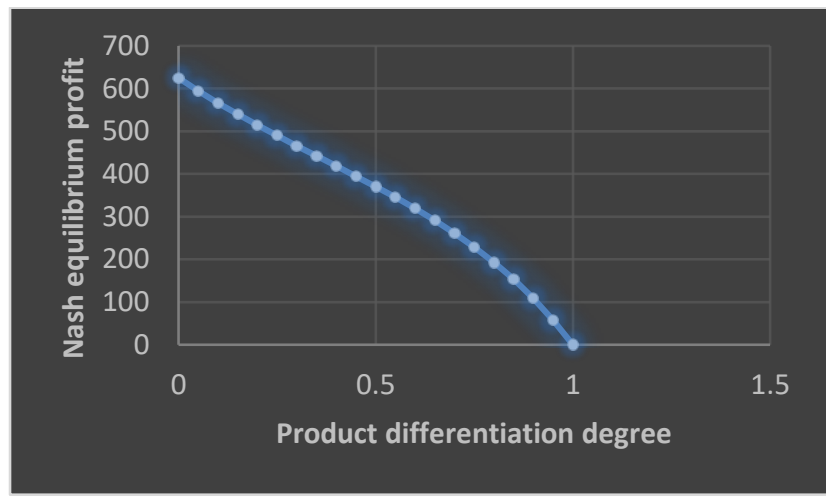

Figure 4. Nash equilibrium profit evolution

\section{Conclusions}

In independent goods case $(\mathrm{d}=0)$, the coefficients of a and $\mathrm{c}$ are equals $(0.5$ each), following opposite trendlines as the degree of products differentiation decreases, however their sum remains unitary, as $\frac{1-d}{2-d}+\frac{1}{1-d}=1$. As a $>\mathrm{c}$, we are witnessing the gradual decrease of the price, from a and $\mathrm{c}$ average value of 55 EUR, down to marginal cost level of 30 EUR;

As for the quantity triggering the equilibrium scenario total coefficients distribution symmetry can be noted in between 0 to 1 interval. Variations are not high, oscillating between 0.5 (maximum - tangible in interval corners) and 0, (4). The explanation is also mathematical (Appendix C), due to the fact that for $q^{* \prime}=-\frac{(a-c)(1-2 d)}{(1+d)^{2}(2-d)^{2}}$ the unique critical point (minimum point also) is $\mathrm{d}=0.5$, with the function showing a decreasing trendline before and and increasing trendline after. It can be noted that the quantity equilibrium level is gradually decreasing from the initial 25 items equilibrium value while bouncing back in homogenous goods scenario.

Profit for equilibrium scenario has a downward trend, starting from 0.25 (a-c) $)^{2}$ down to zero value for homogeneous goods (so-called Bertrand paradox). Math principles are one more time to be noted as $\pi^{* \prime}=-\frac{2(a-c)^{2}\left(d^{2}-d+1\right)}{(1+d)^{2}(2-d)^{3}}$, strictly negative expression (Appendix D) therefore a decreasing function. Moreover the graph shows a decreasing profit trend from 625 EUR to the breakeven point (zero profit). 
www.conferenceie.ase.ro

\section{References}

[1] J. Von Neumann, O. Morgenstern, Theory of games and economic behavior, Princeton University Press, 1944.

[2] J.S. Bain, "Barriers to New Competition, their character and consequences in Manufacturing", Harvard University Press (1956)

[3] P. Sylos-Labini, Oligopolio e progresso tecnico. Milano, Giuffre' 1957, pp. 207, L. 1000

[4] F. Modigliani, "New developments on the oligopoly front", Journal of political Economy, Vol. 66 (1958), pp. 215-232

[5] X. Vives, Oligopoly Pricing: Old Ideas and New Tools. MIT Press, Cambridge, 2001

[6] J. Bertrand, Review of Théorie Mathématique de la Richesse Sociale and Recherches sur les Principles Mathématique de la Théorie des Richesses. Journal des Savants (1883), pp. 499-508.

[7] A. Dixit, "A model of duopoly suggesting a theory of entry barriers". Bell Journal of Economics, Vol. 10 (1979), pp. 20-32.

[8] N. Singh, and X. Vives, "Price and Quantity Competition in a Differentiated Duopoly," Rand Journal of Economics, Vol. 15, No. 4, 1984, pp. 546-554.

[9] J. Häckner, "A note on price and quantity competition in differentiated Oligopolies", Journal of Economic Theory, Vol 93 (2000), pp. 233-239.

[10] P. Zanchettin, "Differentiated duopoly with asymmetric costs", Journal of Economic Management Strategy, Vol 15 (2006), pp. 999-1015.

[11] C.H. Tremblay, M.J. Tremblay, V.J. Tremblay, "A general Cournot-Bertrand model with homogenous goods", Theoretical Economics Letters 1 (2011) 38-40.

[12] E. Ahmed, M.F. Elettreby, A.S. Hegazi, "On Puu's incomplete information formulation for the standard and multi-team bertrand game", Chaos, Soliton Fractals 30 (2006) 11801184.

[13] J.X. Zhang, Q.L. Da, Y.H. Wang, "The dynamics of Bertrand model with bounded rationality", Chaos, Solitons Fractals 39 (2009), pp. 2048-2055.

[14] C.H. Tremblay, and V.J. Tremblay, "The Cournot-Bertrand Model and the Degree of Product Differentiation," Eco-nomics Letters, Vol. 111, No. 3, 2011, pp. 233-235.

[15] E. Ahmed, A.A. Elsadany, T. Puu, "On Bertrand duopoly game with differentiated goods", Applied Mathematics and Computation 251 (2015) 169-179

[16] Q.G. Yi, X.J. Zeng, "Complex dynamics and chaos control of duopoly Bertrand model in Chinese air-conditioning market”, Chaos, Solitons \& Fractals 76 (2015) 231-237

[17] H. Sonneschein, "The Dual of Duopoly Is Complementary Monopoly: or. Two of Cournot's Theories Are One", Journal of Political Economy, Vol. 76 (1968), pp. 316-318.

[18] A. Imperato, A. Andrei, G. Oprescu, M. Roman, Reglarea Cibernetica in Sistemul Pietei Bunurilor si Serviciilor. Editura ASE, 2004

[19] A. Dixit, "Comparative statics for oligopoly" International Economic Review, Vol. 27 (1986), pp. 107-122

[20] M. Machado, "Economia Industrial", Cap 3.4 - Competencia en precios Modelo de Bertrand. Internet: https://www.academia.edu/16477977/1_1.Monopolio_modelo_basico [Jan. 20, 2019]. 


\section{Appendix A}

$\left\{\begin{array}{l}\frac{\partial \pi_{1}}{\partial p_{1}}=\mathrm{m}-2 \mathrm{n} p_{1}+l p_{2}+\mathrm{nc}=0 \\ \frac{\partial \pi_{2}}{\partial p_{2}}=\mathrm{m}-2 \mathrm{n} p_{2}+l p_{1}+\mathrm{nc}=0\end{array} \rightarrow\left\{\begin{array}{l}p_{1}=\frac{\mathrm{m}+l p_{2}+\mathrm{nc}}{2 n}=\frac{a-a d+d p_{2}+c}{2} \\ p_{1}=\frac{2 n p_{2}-m-\mathrm{nc}}{l}=\frac{2 p_{2}-a-c+a d}{d}\end{array}\right.\right.$ where $m=\frac{\mathrm{a}(1-d)}{1-d^{2}}, n=\frac{1}{1-d^{2}}, \mathrm{l}=\frac{d}{1-d^{2}}$. By substitution:

$\frac{d}{1-d^{2}} \frac{a-a d+d p_{2}+c}{2}=-\frac{a-a d}{1-d^{2}}+\frac{2 p_{2}}{1-d^{2}}-\frac{c}{1-d^{2}} \rightarrow a d-a d^{2}+d^{2} p_{2}+c d=$ $=-2 a+2 a d+4 p_{2}-2 c \rightarrow p_{2}\left(4-d^{2}\right)=-a d(1+d)+2 a+2 c+c d$.

Therefore $p_{2}^{*}=\frac{-a d(1+d)+2 a+2 c+c d}{4-d^{2}}=\frac{a(1-d)+c}{2-d}$ and similarly $p_{1}^{*}=\frac{a(1-d)+c}{2-d}=p_{2}^{*}$

Equilibrium prices are identical. Identifying the appropriate quantities involve:

$q_{1}^{*}=\mathrm{m}-\mathrm{n} p_{1}^{*}+\mathrm{l} p_{2}^{*}=\frac{\mathrm{a}(1-d)}{1-d^{2}}+\frac{\mathrm{d}-1}{1-d^{2}} \frac{-a d(1+d)+2 a+2 c+c d}{4-d^{2}}=\frac{4 a-4 a d-a d^{2}-a d^{3}+a d}{\left(1-d^{2}\right)\left(4-d^{2}\right)}+$ $\frac{a d^{2}-2 a-2 c-c d-a d^{2}-a d^{3}+2 a d+2 c d+c d^{2}}{\left(1-d^{2}\right)\left(4-d^{2}\right)}=\frac{(a-c)\left(2-d-d^{2}\right)}{\left(1-d^{2}\right)\left(4-d^{2}\right)}=\frac{a-c}{(1+d)(2-d)}=q_{2}^{*}$

The equilibrium quantities are the same for the two players. At this point, we can also calculate the profit obtained in the Nash equilibrium scenario: $\pi_{1}^{*}=\pi_{2}^{*}=\left(p^{*}-c\right) q^{*}=$ $\frac{-a d^{2}-a d+2 a+2 c+c d-4 c+c d^{2}}{4-d^{2}} * \frac{(a-c)}{(1+d)(2-d)}=\frac{(a-c)\left(2-d-d^{2}\right)}{4-d^{2}} * \frac{(a-c)}{(1+d)(2-d)}=\frac{(a-c)^{2}(1-d)}{(2-d)^{2}(1+d)}$

\section{Appendix B}

Table 1. Simulation of price, quantity and profit evolution

\begin{tabular}{|c|c|c|c|}
\hline $\mathbf{d}$ & $\mathbf{p}$ & $\mathbf{q}$ & $\Pi$ \\
\hline 0 & $0.5 * \mathrm{a}+0.5 * \mathrm{c}$ & $0.5 *(\mathrm{a}-\mathrm{c})$ & $0.25 *(\mathrm{a}-\mathrm{c})^{2}$ \\
\hline 0.05 & $0.487179 * \mathrm{a}+0.512821 \mathrm{c}$ & $0.4884 *(\mathrm{a}-\mathrm{c})$ & $0.237939 *(\mathrm{a}-\mathrm{c})^{2}$ \\
\hline 0.1 & $0.473684 * \mathrm{a}+0.526316 * \mathrm{c}$ & $0.478469 *(\mathrm{a}-\mathrm{c})$ & $0.226643 *(\mathrm{a}-\mathrm{c})^{2}$ \\
\hline 0.15 & $0.459459 * \mathrm{a}+0.540541 * \mathrm{c}$ & $0.470035 *(\mathrm{a}-\mathrm{c})$ & $0.215962 *(\mathrm{a}-\mathrm{c})^{2}$ \\
\hline 0.2 & $0.444444 * \mathrm{a}+0.555556 * \mathrm{c}$ & $0.462963 *(\mathrm{a}-\mathrm{c})$ & $0.205761 *(\mathrm{a}-\mathrm{c})^{2}$ \\
\hline 0.25 & $0.428571 * \mathrm{a}+0.571429 * \mathrm{c}$ & $0.457143 *(\mathrm{a}-\mathrm{c})$ & $0.195918 *(\mathrm{a}-\mathrm{c})^{2}$ \\
\hline 0.3 & $0.411765 * \mathrm{a}+0.58823 *^{*} \mathrm{c}$ & $0.452489 *(\mathrm{a}-\mathrm{c})$ & $0.186319 *(\mathrm{a}-\mathrm{c})^{2}$ \\
\hline 0.35 & $0.393939 * \mathrm{a}+0.606061 * \mathrm{c}$ & $0.448934 *(\mathrm{a}-\mathrm{c})$ & $0.176853 *(\mathrm{a}-\mathrm{c})^{2}$ \\
\hline 0.4 & $0.375 * \mathrm{a}+0.625 * \mathrm{c}$ & $0.446429 *(\mathrm{a}-\mathrm{c})$ & $0.167411 *(\mathrm{a}-\mathrm{c})^{2}$ \\
\hline 0.45 & $0.354839 * \mathrm{a}+0.645161 * \mathrm{c}$ & $0.444939 *(\mathrm{a}-\mathrm{c})$ & $0.157882 *(\mathrm{a}-\mathrm{c})^{2}$ \\
\hline 0.5 & $0.333333 * \mathrm{a}+0.666667 * \mathrm{c}$ & $0.444444 *(\mathrm{a}-\mathrm{c})$ & $0.148148 *(\mathrm{a}-\mathrm{c})^{2}$ \\
\hline 0.55 & $0.310345 * \mathrm{a}+0.689655^{*} \mathrm{c}$ & $0.444939 *(\mathrm{a}-\mathrm{c})$ & $0.138084 *(\mathrm{a}-\mathrm{c})^{2}$ \\
\hline 0.6 & $0.285714 * \mathrm{a}+0.714286 * \mathrm{c}$ & $0.446429 *(\mathrm{a}-\mathrm{c})$ & $0.127551 *(\mathrm{a}-\mathrm{c})^{2}$ \\
\hline 0.65 & $0.259259 * \mathrm{a}+0.740741 * \mathrm{c}$ & $0.448934 *(\mathrm{a}-\mathrm{c})$ & $0.11639 *(\mathrm{a}-\mathrm{c})^{2}$ \\
\hline 0.7 & $0.230769 * \mathrm{a}+0.769231 * \mathrm{c}$ & $0.452489 *(\mathrm{a}-\mathrm{c})$ & $0.10442 *(\mathrm{a}-\mathrm{c})^{2}$ \\
\hline 0.75 & $0.2 * \mathrm{a}+0.8 * \mathrm{c}$ & $0.457143 *(\mathrm{a}-\mathrm{c})$ & $0.091429 *(\mathrm{a}-\mathrm{c})^{2}$ \\
\hline 0.8 & $0.166667 * \mathrm{a}+0.83333 *^{*} \mathrm{c}$ & $0.462963 *(\mathrm{a}-\mathrm{c})$ & $0.07716 *(\mathrm{a}-\mathrm{c})^{2}$ \\
\hline 0.85 & $0.130435 * \mathrm{a}+0.869565 * \mathrm{c}$ & $0.470035 *(\mathrm{a}-\mathrm{c})$ & $0.061309 *(\mathrm{a}-\mathrm{c})^{2}$ \\
\hline
\end{tabular}


www.conferenceie.ase.ro

\begin{tabular}{|c|c|c|c|}
0.9 & $0.090909 * \mathrm{a}+0.909091 * \mathrm{c}$ & $0.478469 *(\mathrm{a}-\mathrm{c})$ & $0.043497 *(\mathrm{a}-\mathrm{c})^{2}$ \\
\hline 0.95 & $0.047619 * \mathrm{a}+0.952381 * \mathrm{c}$ & $0.4884 *(\mathrm{a}-\mathrm{c})$ & $0.023257 *(\mathrm{a}-\mathrm{c})^{2}$ \\
\hline 1 & $\mathrm{c}$ & $0.5 *(\mathrm{a}-\mathrm{c})$ & 0 \\
\hline
\end{tabular}

\section{Appendix C}

$$
\begin{aligned}
q^{*}=\frac{a-c}{(1+d)(2-d)} \rightarrow q^{* \prime}=\frac{\Delta q^{*}}{\Delta d}=-(a-c) \frac{[(1+d)(2-d)]^{\prime}}{[(1+d)(2-d)]^{2}} \\
=-(a-c) \frac{[2-d+(1+d)(-1)]}{(1+d)^{2}(2-d)^{2}}=\frac{(a-c)(1-2 d)}{(1+d)^{2}(2-d)^{2}}
\end{aligned}
$$

With the exception of the $1-2 \mathrm{~d}$ term, all other brackets are positive, so the sign of the derivative is given by its sign. As $1 / 2$ is the critical value, we get:

$$
\left\{\begin{array} { l } 
{ 1 - 2 d < 0 ( \forall ) d \in [ 0 ; \frac { 1 } { 2 } ) } \\
{ 1 - 2 d > 0 ( \forall ) d \in ( \frac { 1 } { 2 } ; 1 ] }
\end{array} \rightarrow \left\{\begin{array} { l } 
{ q ^ { * \prime } < 0 ( \forall ) d \in [ 0 ; \frac { 1 } { 2 } ) } \\
{ q ^ { * \prime } > 0 ( \forall ) d \in ( \frac { 1 } { 2 } ; 1 ] }
\end{array} \rightarrow \left\{\begin{array}{l}
q^{*} \downarrow(\forall) d \in\left[0 ; \frac{1}{2}\right) \\
q^{*} \uparrow(\forall) d \in\left(\frac{1}{2} ; 1\right]
\end{array}\right.\right.\right.
$$

\section{Appendix D}

$$
\begin{aligned}
\pi^{*}= & \frac{(a-c)^{2}(1-d)}{(2-d)^{2}(1+d)} \rightarrow \pi^{* \prime}=\frac{\Delta \pi^{*}}{\Delta d}=(a-c)^{2} \frac{-(2-d)^{2}(1+d)-(1-d)\left[(2-d)^{2}(1+d)\right]^{\prime}}{\left[(2-d)^{2}(1+d)\right]^{2}}= \\
= & (a-c)^{2} \frac{-\left(4-4 d+d^{2}\right)(1+d)-(1-d)\left[-2(2-d)(1+d)+(2-d)^{2}\right]}{\left[(2-d)^{2}(1+d)\right]^{2}} \\
= & (a-c)^{2} \frac{-4-4 d+4 d+4 d^{2}-d^{2}-d^{3}-(1-d)\left(2 d^{2}-2 d-4+4-4 d+d^{2}\right)}{\left[(2-d)^{2}(1+d)\right]^{2}} \\
= & (a-c)^{2} \frac{-d^{3}+3 d^{2}-4-(1-d)\left(3 d^{2}-6 d\right)}{\left[(2-d)^{2}(1+d)\right]^{2}} \\
= & (a-c)^{2} \frac{-d^{3}+3 d^{2}-4-3 d^{2}+6 d+3 d^{3}-6 d^{2}}{\left[(2-d)^{2}(1+d)\right]^{2}}=(a-c)^{2} \frac{2 d^{3}-6 d^{2}+6 d-4}{(2-d)^{4}(1+d)^{2}} \\
& =(a-c)^{2} \frac{2\left(d^{3}-3 d^{2}+3 d-2\right)}{(2-d)^{4}(1+d)^{2}}=(a-c)^{2} \frac{2(d-2)\left(d^{2}-d+1\right)}{(2-d)^{4}(1+d)^{2}} \\
& \quad=-(a-c)^{2} \frac{2\left(d^{2}-d+1\right)}{(2-d)^{3}(1+d)^{2}}<0 \rightarrow \pi^{*^{\prime}}<0(\forall) d \in[0 ; 1) \rightarrow \pi^{*} \downarrow(\forall) d \in[0 ; 1)
\end{aligned}
$$

